\title{
Participating in primary care
}

\author{
Differing styles of psychiatric liaison
}

\author{
A. R. K. Mitchell, Community Psychiatrist, Cambridge Health Authority
}

Traditionally, general practitioners and psychiatrists relate to one another through a system of cross referrals, from primary care to secondary care and back again, the referral being initiated by the GP through a request for a domiciliary visit or more usually for an out-patient assessment of the clinical problem. However, in the mid-1960s, individual psychiatrists began to report a new way of working, which consisted of the psychiatrist going by invitation into GPs' surgeries or health centres to work directly with the general practitioners and with other members of the primary health care team. A survey undertaken by Strathdee \& Williams of the General Practice Research Unit of the Institute of Psychiatry, showed that by 1984 in England and Wales, one psychiatric consultant in five, sometimes with, sometimes without, junior staff, spent some time in a general practice setting. At the College meeting in Cambridge (April 1988), Pullen reported that in Scotland a similar survey showed that as many as $\mathbf{4 0}$ to $50 \%$ of psychiatric consultants spent some time in primary care settings.

These liaison-attachment schemes are as varied as the psychiatrists and general practitioners taking part in them, but five principal styles or models can be identified out of my own experience in working in this way through contact with family doctors in both urban and rural settings in Cambridgeshire.

\section{(1) The shifted out-patient model}

The psychiatrist, by arrangement, goes regularly into a health centre or GP surgery, there to see a number of patients who might otherwise be seen in the OutPatient Department of the local psychiatric service.

\section{Advantages}

(a) Referral is made more speedily and easily

(b) There is less stigma for patients and relatives in being seen by a psychiatrist in the GP premises.

\section{Limitations}

(a) Little is gained unless the psychiatrist can spend some time in face to face contact with referring GPs and this means time has to be set aside for this purpose. (b) The psychiatrist is spending time away from the specialist mental health care services back at 'base'.

\section{(2) Selected consultation model}

The psychiatrist goes into the health centre or GP surgery as before, but arranges to speak to the referring doctor before the patient is seen, and again afterwards for a few moments, to give immediate verbal feedback, followed up by a written report later.

\section{Advantages}

(a) There is regular contact between the GPs and psychiatrist.

(b) Hidden agendas, not usually spelled out in referring letters, can be articulated and responded to.

\section{Limitations}

(a) Limitation of time means fewer patients can be seen in a given session and time has to be set aside for meeting with the GPs face to face.

(b) There has to be conscious selection by the general practitioner of who most needs to be seen, or of whose ongoing management will best be clarified by this procedure.

Oxman \& Smith (1980)

\section{(3) Modified Balint model}

The psychiatrist meets regularly with a group of general practitioners from a given health centre or a number of general practitioners from differing surgeries or health centres, to discuss in a group setting the dilemmas of diagnosis and management presented to these doctors by certain patients and relatives. The focus of attention tends to be on the difficulties in the general practitioner/patient relationship, rather than diagnosis of disorder within the patient, using the principles of mental health consultation. One such group has gone on to study particular aspects of 'difficult patients'; for example, the frequent attender, or those patients whom the doctor dislikes but feels he must go on seeing despite feeling he is doing nothing for the patient. 


\section{Advantages}

(a) The subtleties of the GP/patient and indeed the GP/psychiatrist relationships can be examined when the group feels confident enough, and there is sufficient safety and mutual trust.

(b) The interaction between members of the given group practice, or the different ways of working at different practices, can be identified and better understood.

\section{Limitations}

(a) This style leads to a certain amount of self examination which is not readily acceptable to all doctors.

(b) The psychiatrist has to have a certain personal style as well as the skills and experience to run such a supervisory group.

Browne \& Freeling (1967)

\section{(4) Joint team consultation model}

A number of colleagues from the mental health care team, for example psychiatrists, clinical psychologists, community psychiatric nurse, social workers etc., meet regularly with their opposite numbers in the primary health care team, for example family doctors, practice nurses, health visitors, attached social worker etc. They may meet altogether in a large group as well as splitting off in pairs for specific mental health consultation and supervision.

\section{Advantages}

(a) Both teams come to learn their similarities and their differences in mutual respect for each other's skills.

(b) The various roles and tasks of each professional can be clearly set out and agreed upon.

\section{Limitations}

(a) Important members are taken away from the base psychiatric unit.

(b) Boundary disputes over patient care responsibilities can arise, but they can also be clarified. World Health Organization (1983)

\section{(5) Tripartite assessment model}

The psychiatrist, by invitation of the general practitioner and patient, sits in the surgery with both, having clarified with the GP beforehand the nature of the difficulty the family doctor and patient are experiencing which may be diagnosis but usually is how to proceed further when things have become "stuck". After the joint consultation, the psychiatrist can make recommendations immediately to the GP on how management might proceed, with the option of returning at a later date for review, if it is felt that that would be helpful.

\section{Advantages}

(a) There is a very personal and immediate contact between GP and psychiatrist.

(b) The psychiatrist can offer a model for proceeding, to both GP and patient.

\section{Limitations}

(a) The psychiatrist must be careful not to replace the general practitioner as doctor of primary care, and not to undermine his authority with the patient. (b) Such procedure takes time, often up to one hour, which must be specifically set aside for this purpose.

Mitchell (1984)

\section{Evaluation of these differing styles}

(1) Number of patients seen (Table 1)

The shifted out-patient model allows the greatest number of patients to be seen and in that sense is the most economic style, followed by the joint team consultation model. Least economic in patient contacts is the modified Balint, followed by the tripartite and selected consultation models. Here, however, the value is more on psychiatrist/GP contact than on the number of patients which can be seen in a given time.

\section{(2) Effect on GP behaviour (Table II)}

Liaison attachment schemes can influence most immediately the number of patients a given general

TABLE I

Number of patients seen

\begin{tabular}{|c|c|c|c|c|}
\hline \multirow[b]{2}{*}{ Model } & \multirow[b]{2}{*}{ Sessions } & \multicolumn{3}{|c|}{ Annual rate (based on 40 week year) } \\
\hline & & New patients & Old patients & Total \\
\hline Shifted out-patient & 2 a week & 160 & 640 & 800 \\
\hline Selected consultation & 1 a month & 30 & 10 & 40 \\
\hline "Balint" & 1 a month & 10 & - & 10 \\
\hline Joint-team & 1 a month & 40 & 120 & 160 \\
\hline Tripartite & as requested & 16 & 4 & 20 \\
\hline
\end{tabular}


TABLE II

Effect on GPS

\begin{tabular}{lcc}
\hline Model & $\begin{array}{c}G P \\
\text { admissions }\end{array}$ & GP skills \\
\hline Shifted out-patient & $\downarrow$ & $\cdot$ \\
Selected consultation & $\downarrow$ & $\uparrow$ \\
"Balint" & $\cdot$ & $\uparrow \uparrow$ \\
Joint-team & $\downarrow$ & $\uparrow$ \\
Tripartite & $\cdot$ & $\uparrow \uparrow \uparrow$ \\
\hline
\end{tabular}

practitioner will admit to the base psychiatric unit, by offering both an alternative to admission, but also hopefully earlier contact in the evolution of the mental disorder, and thus minimising the risk of an acute crisis for which admission may be the only practical answer (Tyrer, Seivewright \& Wollerton, 1984). In addition, over time repeated contact between psychiatrist and GP results in a learning process for each: the psychiatrist becomes more aware of what both GP and patient hope for in the referral, and thus becomes more sensitive to GP and patient needs, while the GP, it is hoped, by being supported in this way, and by being offered a role model appropriate to general practice, learns greater skills in diagnosing and managing mental disorder in the primary care settings.

(a) Reduction of admission is most likely to occur with the shifted-out patient, the selected consultation and the joint team consultation styles, because here there is the most immediate sharing of responsibility for maintaining management at home, and the possibility of early contact with the first evidence of the mental disorder. The modified Balint and tripartite styles do not of themselves alter admission directly because the patients offered for joint consultation are those the GP wishes to continue to manage himself in primary care.

(b) GP skills, on the other hand, are best developed in the tripartite model because of the direct contact of GP and patient with the psychiatrist together with maximum opportunity for the discussion of hidden agendas and opportunity for problem related learning. The Balint model comes next with its emphasis more on group learning and modification of group attitudes, with less opportunity for immediate learning on a personal one-to-one basis. GP skills will only be improved in the other models if time is set aside for meeting face to face, otherwise the opportunities for learning are no greater than in traditional out-patient referrals.

In summary, therefore, it would appear that if the principal motivation is to see the greatest number of patients, and thereby reduce admission to the base psychiatric hospital, then the shifted out-patient and joint team consultation model are the best choice; but where the principal motivation is the increase of psychiatrist's sensitivity to GP needs and the increase of GP mental health skills, then the best choice would appear to be the tripartite assessment and the modified Balint model.

All these liaison attachment models have their own particular advantages and limitations serving different motivations in the psychiatrist and GPs involved, but happily they all fulfil one definition of a liaison, namely "a temporary alliance for mutual benefit", and at the same time resist the temptation to fall into another definition, namely "opportunities for illicit intimacy".

\section{References}

Browne, K. \& Freeling, P. (1967) The Doctor-Patient Relationship. Edinburgh and London: Livingston.

MitChell, A. R. K. (1984) Psychiatrists and general practitioners: the tripartite interview. Psychiatry in Practice, 3, 20-22.

Oxman, T. \& Smith, R. (1980) Consultation-liaison psychiatry within a family practice. Social Psychiatry, 17, 101-107.

Strathide, G. \& Williams, P. (1984) A survey of psychiatrists in primary care: the silent growth of a new service. Journal of the Royal College of General Practitioners, 34, 615-618.

TYRER, P. (1984) Psychiatric clinics in general practice: an extension of community care. British Journal of Psychiatry, 145, 9-14.

-, SeIVEWRight, N. \& Woller TON, S. (1984) General practice psychiatric clinics: impact in psychiatric services. British Journal of Psychiatry, 145, 15-19.

World Health Organization, (1983) First Contact Mental Health Care. Report of a Working Group. Copenhagen, WHO Regional Office for Europe. 